LINGUA, Vol. 14, No. 1, Maret 2017

p ISSN: 1979 9411; e ISSN: 2442 238X

Http://lingua.pusatbahasa.or.id; Email:presslingua@gmail.com

Center of Language and Culture Studies, Surakarta, Indonesia

Sam'un, Ahmad. 2017. Simbol dan Makna Budaya NyawE? dan Beras Pati: Upaya Pemertahanan Bahasa Masyarakat Sasak. Lingua (2017), 14(1): 79 88.

\title{
SIMBOL DAN MAKNA BUDAYA NYAWE? DAN BERAS PATI: UPAYA PEMERTAHANAN BAHASA MASYARAKAT SASAK
}

\author{
Ahmad Sam'un \\ PascasarjanaPendidikan Bahasa Indonesia \\ Universitas Mataram \\ Jl. Pemuda No. 35 Mataram 83125, Nusa Tenggara Barat \\ Email: samiunlutfi9@yahoo.com \\ Diterima tanggal: 10 Desember 2016 \\ Diterima untuk diterbitkan tanggal: 1 Januari 2017
}

\begin{abstract}
This study is aimed to describe meaning represented in symbols of rituals of NyawE and Beras Pati in Sasak society. The study used ethnolinguistics approach, assigning native speakers of Sasak language residing in the city of Mataram. Data were collected using observation, interviews and document analysis. The study revealed that symbols in the tradition are identified in terms of bamboo (terEng) and palm leaf (daon nao) having spiritual meanings for the Sasak society. Nowdays, the symbols have been prevented as the existance of Sasak tribe especially for elderly generation.
\end{abstract}

Keywords: symbol, meaning, NyawE culture, Beras Pati.

Masyarakat ialah kumpulan individu-individu yang hidup bersama dan memiliki budaya masing-masing, baik budaya yang memiliki persamaan dengan budaya-budaya yang ada maupun perbedaan yang menjadi ciri khasnya. Budaya dalam sebuah masyarakat biasanya dijadikan sebagai tolok ukur kekhasan dalam kelompok dan sekaligus dijadikan sebagai pengikat perilaku kelompok masyarakat. Pernyataan penulis di atas sejalan dengan apa yang dimaksudkan dalam Hipotesa Sapir-Whorf yakni bahasa merupakan sarana mengkomunikasikan gagasan dan persaaan secara objektif yang sekaligus juga merupakan ungkap-verbal yang khas bagi nilai-nilai budaya yang bersifat relatif (dalam Kadarisman, 2010:48). Selanjutnya Kadarisman (2010:1) mengemukakan bahwa bahasa yang berfungsi sebagai alat komunikasi ada dan tumbuh dalam suatu lingkungan budaya, dan nilai-nilai budaya sering terungkap secara khas dalam bahasa setempat.

Salah satu masyarakat yang ada saat ini adalah masyarakat Sasak, desa Perina, Kecamatan Jonggat, Lombok Tengah. Masyarakat Sasak, desa Perina sebagai salah satu kelompok masyarakat yang masih bertahan sampai dewasa ini memiliki budaya yang masih dijaga dan dijalankan oleh kelompok masyarakatnya. Dewasa ini, melalui budaya tidak jarang atau bahkan bisa dipastikan seseorang dapat mengetahui bahasa yang khas 
LINGUA, Vol. 14, No. 1, Maret 2017

p ISSN: 1979 9411; e ISSN: 2442 238X

Http://lingua.pusatbahasa.or.id; Email:presslingua@gmail.com

Center of Language and Culture Studies, Surakarta, Indonesia

Sam'un, Ahmad. 2017. Simbol dan Makna Budaya NyawE? dan Beras Pati: Upaya Pemertahanan Bahasa Masyarakat Sasak. Lingua (2017), 14(1): 79 88.

dalam sebuah kelompok masyarakat. Singkatnya, pemertahanan atau pelestarian budaya berarti mempertahankan sekaligus melestarikan bahasa. Penelitian ini dilakukan sebagai bentuk pemertahanan sekaligus pelestarian budaya dan bahasa dari pengaruh budaya barat yang semakin terlihat. Sebagai akibat dari pengaruh budaya barat, tidak jarang sebelum penelitian ini dilakukan para generasi muda khususnya mengabaikan budaya yang telah berjalan. Akibat dari perilaku tersebut hampir semua generasi muda yang ada di desa Perina, kecamatan Jonggat, Lombok Tengah tidak mengetahui makna dari simbol budaya NyawE? dan Beras Pati (selanjunya disingkat BNBP) yang dijalankan.

Budaya yang telah dijalankan oleh masyarakat Sasak, desa Perina selama ini memiliki simbol dalam pelaksanaannya. simbol-simbol inilah kemudian yang akan diteliti oleh penulis untuk kemudian dapat diketahui makna yang tersimpan di dalamnya. Makna-makna yang ada kemudian akan dijabarkan oleh penulis berdasarkan hasil penelitian menggunakan alat komunikasi manusia yaitu bahasa. Sehingga tujuan akhir dari penelitian ini kemudian biasa menjelaskan bagaimana simbol dan makna BNBP hubungannya dengan pemertahanan bahasa Masyarakat Sasak Desa Perina, Kecamatan Jonggat, Lombok Tengah sebagai salah satu bagian dari keberagamaan bahasa yang dimiliki oleh bangsa Indonesia.

Masyarakat sebagai kumpulan individu-individu yang hidup secara berkelompok, serta memiliki cara hidup tersendiri atau pun memiliki kesamaan antara kelompok mayarakat yang satu dan kelompok masyarakat yang lainnya. Pendapat di atas sejalan dengan apa yang dikemukakan oleh M. J. Herkovits dalam Abidin dan Saebani (2014:43) yaitu masyarakat merupakan kelompok individu yang terorganisasikan dengan mengikuti pola hidup tertentu. Selanjutnya dalam buku yang sama yaitu Abidin dan Saebani (2014:43) Linton menjelaskan bahwa masyarakat merupakan setiap kelompok individu-individu (manusia) yang hidup dan bekerja bersama-sama mengorganisasikan diri sebagai satu kesatuan dengan batas-batas tertentu. Batas-batas tertentu dalam pernyataan Linton di atas sangat erat kaitannya dengan salah satu unsur penting bagi eksistensi sosial masyarakat, yaitu kontrol sosial (social control). Kontrol sosial berfungsi untuk mengatur dan/atau mengawasi sistem serta prosedur yang mengatur kegiatan dan tindakan anggota masyarakat dalam kehidupan sosial (Abidin dan Saebani, 2014:45). Pengawas sosial dalam hal ini meliputi sistem ilmu pengetahuan, ilmu teknik empiris maupun nonempiris yang digunakan untuk mengelola lingkungan dan mengatur sikap dan prilaku magis atau keagamaan, beberapa diantaranya yaitu etika dan ritual.

Etika dan ritual merupakan kegiatan yang sangat erat kaitannya dengan kebudayaan. Menurut Geertz (dalam Abidin dan Saebani, 2014:38) kebudayaan merupakan jaringan yang dibangun oleh manusia untuk mencari makna. Jaringanjaringan tersebut kemudian dibentuk/dihubungkan sedemikian indah dan baiknya oleh manusia, dengan alasan bahwa dalam kehidupan manusia terdapat berbagai macam ekspresi dan isyarat-isyarat yang harus ditafsirkan maknanya. Ekspresi manusia memiliki berbagai cara dalam rangka mengungkapkan pemikiran, perasan, gagasan dan seterusnya serta sangat erat kaitannya dengan tingkah laku. Selain itu, Kupper (dalam 
LINGUA, Vol. 14, No. 1, Maret 2017

p ISSN: 1979 9411; e ISSN: 2442 238X

Http://lingua.pusatbahasa.or.id; Email:presslingua@gmail.com

Center of Language and Culture Studies, Surakarta, Indonesia

Sam'un, Ahmad. 2017. Simbol dan Makna Budaya NyawE? dan Beras Pati: Upaya Pemertahanan Bahasa Masyarakat Sasak. Lingua (2017), 14(1): 79 88.

Abidin dan Saebani, 2014:39) mendefinisikan kubudayaan sebagai sistem gagasan yang menjadi pedoman dan pengarah bagi kehidupan manusia bersikap dan berperilaku secara individu maupun kelompok dalam kehidupan bermasyarakat. Salah satu caranya adalah apa yang disebutkan sebagai BNBP dalam penelitian ini.

Perilaku manusia dalam kehidupan bermasyarakat tidak terlepas dari bahasa sebagai alat kemunikasinya. Kadarisman (2010:1) mengemukakan bahwa bahasa yang berfungsi sebagai alat komunikasi ada dan tumbuh dalam suatu lingkungan budaya, dan nilai-nilai budaya sering terungkap secara khas dalam bahasa setempat. Kalimat di atas mengindikasikan bahwa bahasa dan budaya memiliki hubungan timbal balik yang sangat erat sebagaimana yang dijelaskan dalam Hipotesa Sapir-Whorf yakni bahasa merupakan sarana mengkomunikasikan gagasan dan persaaan secara obyektif yang sekaligus juga merupakan ungkap-verbal yang khas bagi nilai-nilai budaya yang bersifat relatif (dalam Kadarisman 2010:48).

Semiotika merupakan ilmu tentang tanda. Menurut Sudjiman dan Van Zoest (dalam Sobur, 2013:16) kata semiotika berasal dari bahasa Yunani semeion yang memiliki arti "tanda" atau seme yang berarti "penafsir tanda" (Cobley dan Jansz dalam Sobur, 2013:16). Saussure sebagai salah salah satu tokoh semiotika di Eropa (Budiman dalam Sobur, 2013:12) menyatakan bahwa semiotika merupakan sebuah ilmu yang mempelajari kehidupan tanda-tanda yang berada di tengah kehidupan masyarakat. sejalan dengan hal di atas (Sobur, 2013:15) mengatakan semiotika merupakan suatu ilmu atau metode untuk mempelajari tanda. Selanjutnya Semiotika adalah teori yang memiliki anggapan bahwa fenomena sosial masyarakat dan kebudayaan itu sebagai tanda, serta mempelajari sistem-sistem, aturan-aturan, konveksi-konveksi yang memungkinkan tanda-tanda yang ada tersebut memiliki makna (Preminger dkk dalam Ratih,2016:1). Tanda oleh Ferdinand de Saussure dan Chales Sanders Peirce dibedakan menjadi beberapa jenis, antara lain: tanda (sign), lambang atau simbol, sinyal (signal), dan lain-lain.

Simbol dan makna memiliki kaitan yang sangat erat dengan bahasa atau dalam buku Chaer (2007:37) yang berjudul Linguistik Umum mengatakan bahwa kata lambang/simbol (selanjutnya disebut simbol) sering kita dengar dalam pembicaraan sehari-hari dari orang-orang di sekeliling kita. Misalnya ketika berbicara tentang bendera kita (Indonesia) Sang Merah Putih sering dikatakan warna merah adalah simbol keberanian dan warna putih adalah simbol kesucian. Simbol merupakan salah satu kajian yang dipelajari dalam ilmu semiotika, yaitu ilmu yang mempelajari/mengkaji tanda-tanda yang ada dalam kehidupan manusia (Chaer, 2007:37).

Secara etimologis simbol (symbol) berasal dari kata Yunani "sym-ballein" yang artinya melemparkan bersama suatu (benda,perbuatan) yang kemudian dikaitkan dengan suatu ide (Sobur, 2013:154). Definisi di atas dapat kita pahami bahwa dalam benda atau perbuatan dalam kehidupan sosial masyarakat terdapat makna yang terkandung di dalamnya. Benda sebagai simbol yang terdapat dalam objek penelitian ini yaitu simbol dan makna BNBP memiliki tujuan dalam pelaksanaan. Simbol yang memiliki tujuan dalam pelaksanaannya sejalan dengan definisi Poerwadarminta (dalam 
LINGUA, Vol. 14, No. 1, Maret 2017

p ISSN: 1979 9411; e ISSN: 2442 238X

Http://lingua.pusatbahasa.or.id; Email:presslingua@gmail.com

Center of Language and Culture Studies, Surakarta, Indonesia

Sam'un, Ahmad. 2017. Simbol dan Makna Budaya NyawE? dan Beras Pati: Upaya Pemertahanan Bahasa Masyarakat Sasak. Lingua (2017), 14(1): 79 88.

Sobur, 2013:156) yaitu simbol merupakan semacam tanda, lukisan, perkataan, dan sebagainya, yang menyatakan suatu hal, atau mengandung maksud tertentu. Simbol dalam penelitian ini sejalan dengan penjelasan Chaer (2007:37) bahwa simbol menandai sesuatu yang lain secara konvensional (kesepakatan), tidak secara langsung dan alamiah.

Sejalan dengan apa yang dikemukakan Chaer, Peirce (dalam Sobur, 2013:156) dalam konsepnya mengatakan simbol diartikan sebagai tanda yang mengacu pada objek tertentu yang berada di luar tanda itu sendiri. Simbol (penanda) dan sesuatu yang ditandakan (petanda) memiliki hubungan yang bersifat konvensional sehingga masyarakat pemakainya mampu menafsirkan ciri hubungan antara simbol dengan objek yang di acu dan menafsirkan maknanya. Makna simbol dalam penelitian ini tentunya mengacu atau berlandaskan pada konteks pemakainnya yaitu BNBP yang dimiliki oleh masyarakat Sasak.

Pernyataan di atas sejalan dengan apa yang dikemukakan oleh Parera (2004:47) dalam bukunya yang berjudul Teori Semantik. Parera mengatakan bahwa makna yang terdapat dalam sebuah kata terikat oleh lingkungan kultural dan ekologis pemakai bahasa tertentu. Selanjutnya Chaer mengatakan bahwa mempelajari simbol adalah jalan satu-satunya untuk dapat mengetahui arti simbol tersebut. Arti atau makna merupakan 'pengertian' atau 'konsep' yang terdapat pada sebuah tanda linguistik (Saussure dalam Chaer (2007:287). Berdasaran penjelasan ahli di atas penulis menyimpulkan bahwa antara simbol dan makna memiliki kaitan yang sangat erat.

Pemertahanan bahasa adalah penggunaan suatu bahasa khususnya jika bahasa tersebut dalam tekanan bahasa lain, secara kontinu oleh pemakai/penuturnya (Trask, 1997:126) dalam http://www.pps.unud.ac.id/thesis/kategori-8-linguistik.html/diunduh pada tanggal 1 Oktober 2016 pukul. 02. 35 Wita). Kaitannya dengan pendapat di atas Bloomfield (1993:326) menyatakan bahasa dalam wapside yang sama merupakan sistem tanda untuk mengungkapkan, membentuk, dan menyimbolkan realitas budaya. Bahasa kaitannya dengan masyarakat sebagai penutur bahasa akan mampu dipertahankan jika semua komponen masyarakat sepakat untuk tetap melestarikannya. Sehingga pemertahanan dalam rangka melestarikan bahasa dapat dilakukan dengan baik dan maksimal. Jika kesepakatan sudah ada maka dapat dipastikan bahasa akan mampu dipertahankan serta dilastarikan oleh para penuturnya.

Sejalan dengan kalimat di atas bahwa pemertahanan bahasa baru akan bisa bisa dilaksanakan atau terjadi apabila komunitas pemakai bahasa secara kolektif tetap memilih menggunakannya, dengan catatan bahwa komunitas tersebut tersebut menggunakannnya dalam ranah semula (Sumarsono, 2011:231-32). Dengan kata lain masyarakat sebagai penutur tidak memilih menggunakan bahasa baru dalam ranah yang pada awalnya diperuntukkan bagi bahasa lama. Menurut Sumarsono ((1990) dalam Chaer dan Agustina (2010:146)) ada beberapa hal yang dapat menunjang usaha pemertahan bahasa, di antaranya: (1) Adanya loyalitas yang tinggi dari masyarakat sebagai penutur sebagai konsekuensi kedudukan dan status bahasanya yang menjadi 
LINGUA, Vol. 14, No. 1, Maret 2017

p ISSN: 1979 9411; e ISSN: 2442 238X

Http://lingua.pusatbahasa.or.id; Email:presslingua@gmail.com

Center of Language and Culture Studies, Surakarta, Indonesia

Sam'un, Ahmad. 2017. Simbol dan Makna Budaya NyawE? dan Beras Pati: Upaya Pemertahanan Bahasa Masyarakat Sasak. Lingua (2017), 14(1): 79 88.

lambang dan identitas diri masyarakat; dan (2) Adanya kesinambungan pengalihan bahasa dari generasi ke genarasi berikutnya.

\section{METODE}

Data sebagai objek kajian tentunya memiliki sumber yang umumnya disebut sumber data. Menurut Muhammad (2011:154) sumber data merupakan asal usul dari apa, siapa dan darimana data diperoleh. Data dalam penelitian ini adalah simbol-simbol dan makna BNBP masyarakat Sasak, desa Perina, Kecamatan Jonggat, Lombok Tengah. Data penelitian ini kemudian akan diperoleh dari Bapak Misbah selaku mantan kepala desa dan bapak Acrat selaku tokoh adat di desa Perinaserta Sawaludin sebagai salah satu tokoh yang dihormati dan disantuni oleh masyarakat desa Perina. Beliau adalah tokoh-tokoh yang penulis anggap memenuhi kriteria yang disebutkan Faisal dalam bukunya Sugiyono (2010:400).

Kumpulan data berupa simbol-simbol BNBP selanjutnya akan dianalisis. Tahap analisis data merupakan suatu aktivitas mengurai data untuk kemudian melahirkan kaidah, atau kaidah-kaidah yang berkenaan dengan fokus kajian objek penelitian, di antaranya dengan menggunakan metode dan teknik. Metode yang digunakan dalam penelitian ini adalah metode cakap dengan teknik cakap semuka, serta dikombinasikan dengan teknik rekam dan teknik catat.

Analisis data dilakukan dalam rangka mengimplisitkan hasil analisis salah satunya seperti deskripsi terkait fokus kajian dalam penelitian (Muhammad, 2011:212). Berdasarkan tujuan tahap analisis data di atas peneliti dapat memberi penerjemahan dan penjelasan tentang Makna BNBP dalam simbol-simbol BNBP masyarakat Sasak, Desa Perina, Kecamatan Jonggat, Lombok Tengah. Penerjemahan dan penjelasan data-data yang sudah diperoleh tersebut kemudian peneliti gunakan untuk mengelompokkan data berdasarkan fokus kajian yang telah dijabarkan, sehingga pengelompokkan data tersebut dapat dideskripsikan sebagai langkah penyajian data hasil penelitian.

\section{HASIL DAN BAHASAN}

Berlandaskan teori yang sudah dijabarkan pada bab sebelumnya, berikut ini adalah hasil analisis data yang dilakukan penulis.

Budaya NyawE? (selanjutnya disingkat BN) merupakan sebuah kegiatan ritual yang dilakukan seseorang pada malam hari sebelum rumah salah seorang anggota masyarakat Sasak dibangun di lahan kosong. Ritual BN dilakukan dengan tujuan yang dipercaya masyarakat agar barang/hal-hal yang tidak baik seperti jin dan sejenisnya pindah dari lahan yang kosong (lokasi pembangunan rumah) tersebut ke tempat yang lain. Ritual BN khusus dilakukan oleh orang yang dikatakan dituakan di dusun atau desa masyarakat Sasak sebagai objek dalam penelitian ini. Lebih tepatnya, ritual BN dilakukan pada malam hari. Simbol BN akan diletakkan di tempat pelaksanan pembangunan rumah masyarakat tersebut. simbol-simbol tersebut adalah:

a. terEng memiliki artinya terang dalam bahasa Indonesia, dan 
LINGUA, Vol. 14, No. 1, Maret 2017

p ISSN: 1979 9411; e ISSN: 2442 238X

Http://lingua.pusatbahasa.or.id; Email:presslingua@gmail.com

Center of Language and Culture Studies, Surakarta, Indonesia

Sam'un, Ahmad. 2017. Simbol dan Makna Budaya NyawE? dan Beras Pati: Upaya Pemertahanan Bahasa Masyarakat Sasak. Lingua (2017), 14(1): 79 88.

b. daon nao atau nao memiliki makna naon (Sasak) atau tahu dalam bahasa Indonesia

Simbol terEng dan nao dalam BN memiliki makna umum, yaitu supaya pihakpihak yang bekerja atau terlibat dalam pembangunan rumah salah seorang anggota masyarakat Sasak memiliki pengetahuan yang luas dan jelas atau terang tentang pekerjaan yang sudah direncanakan sebelumnya, sehingga tidak terjadi hambatan dalam pelaksanaannya. Oleh sebab itu, kedua simbol yang telah disebutkan pada kalimat sebelumnya sangat penting dalam pelaksanaan ritual BN. Selanjutnya pada proses pelaksanaan ritual $\mathrm{BN}$, akan dilaksanakan proses bebangar/ngebangar. Ngebangar dalam kebudayaan masyarakat Sasak memiliki makna ngebang. Ngebang dalam bahasa Indonesia artinya mengumandangkan azan. Lantunan suara azan yang dikumandangkan oleh pelaku (orang yang dituakan) harus dilakukan dengan suara yang kecil. Setelah azan selesai dikumandangkan, selanjutnya akan disiapkan air dengan wadah teko.

c. Air yang dalam bahasa sasak disebut ai?.

Air dalam kebudayaan masyarakat Sasak bermakna `mbel bao, enyet dan tenang. Embelbao dalam bahasa Indonesia memiliki makna sejuk. Secara umum, makna kesejukan yang dirasakan menyangkut akal pikiran dan perasaan pekerja dan pemilik rumah sehingga dalam proses pelaksanaan kegiatan pembangunan rumah kedua belah pihak tidak mengalami pertentangan pendapat yang dapat mengakibatkan pertengkaran, walaupun jika nantinya terjadi pertentangan maka diharapkan pertentangan tersebut dapat diselesaikan dengan baik. Lahan kosong sebagai tempat pembangunan rumah salah seorang anggota masyarakat Sasak tersebut kemudian akan dikelilingi oleh siraman air. Setelah ritual BN selesai dilakukan pada malam harinya maka keesokan harinya akan disiapkan ritual Beras Pati.

\section{Budaya Beras Pati (selanjutnya disingkat BP).}

BP milikikaitan yang sangat erat dengan BN. Singkatnya BP merupakan penyempurna BN dalam proses pelaksanaan ritual tersebut. Ritual BP memiliki simbolsimbol yang digunakan dengan makna berbeda-beda. Simbol-simbol tersebut adalah sebagai berikut:

\section{a. beras kuning dan uang}

Beras kuning dan uang dalam ritual kebudayaan BP merupakan simbol anugerah dan sekaligus nikmat Tuhan Yang Maha Esa. Simbol beras kuning dan uang digunakan masyarakat Sasak sebagai perwujudan rasa syukur terhadap anugrah Tuhan YME. Selain itu, simbol ini memiliki tujuan yang dipercaya sebagai bahan makanan makhluk yang tidak dilihat dengan kasat mata seperti jin dan sejenisnya. Pada ritual BNBP simbol beras kuning dan uang akan ditebar di lahan tempat berlangsungya kegiatan atau 
LINGUA, Vol. 14, No. 1, Maret 2017

p ISSN: 1979 9411; e ISSN: 2442 238X

Http://lingua.pusatbahasa.or.id; Email:presslingua@gmail.com

Center of Language and Culture Studies, Surakarta, Indonesia

Sam'un, Ahmad. 2017. Simbol dan Makna Budaya NyawE? dan Beras Pati: Upaya Pemertahanan Bahasa Masyarakat Sasak. Lingua (2017), 14(1): 79 88.

lahan tempat pembangunan rumah salah satu anggota masyarakat Sasak. Beras kuning dan uang tersebut kemudian akan ditebar oleh pelaku ritual.

b. bua? yang dalam bahasa indonesia dikenal dengan nama buah pinang.

Simbol buah pinang dalam pelaksanaan ritual kebudayaan BP memilik makna hati. Hati yang dimaksudkan adalah hati pemilik rumah, tuan rumah atau dalam budaya Begawe dikenal dengan istilah EpEn gawe serta pekerja dan/atau orang lain yang terlibat dalam kegiatan tersebut (pembangunan rumah dan acara begawe). Bua? sebagai perwujudan hati dalam pelaksanaan budaya BNBP berjumlah dua atau satu. Jika jumlah yang digunakan satu maka pinang tersebut akan dibelah menjadi dua. Sehingga diharapkan kedua belah pihak dihati/perasaannya memiliki tujuan yang sama.

c. bunge yang dalam bahasa Indonesia dikenal dengan nama kapas.

Kapas dalam ritual kebudayaan BP memiliki makna ringan. Ringan artinya umumnya adalah masyarakat yang terlibat dalam pelaksanaan kegiatan memiliki rasa yang dapat dikatakan tidak memiliki beban di dalam hati dan pemikirannya. Dengan kata lain orang-orang yang terlibat tidak merasa terbebani dengan apa yang sedang dikerjakan.

Pelaksanaan ritual kebudayaan BNBP pada kegiatan pembangunan rumah memiliki simbol-simbol. Selanjutnya dalam kegiatan begawe ada beberapa simbol tambahan yang digunakan masyarakat Sasak. Simbol-simbol tersebut adalah sebagai berikut:

d. apuh atau dalam bahasa Indonesia dekenal dengan nama bubuk kapur (kapur sisirh).

Bubuk kapur dalam ritual BNBP memiliki makna perasaan yang suci dan bersih sehingga pelaksanaan ritual ditujukan agar buah pinang sebagai simbol dari hati akan menjadi suci dengan tujuan akhir supaya tidak ada perasaaan negatif yang timbul.

e. roko? atau dalam bahasa indonesia dikenal dengan nama rokok.

Rokok memiliki makna rukun. Rukun yang memiliki makna leksikal baik dan damai, tidak bertengkar, serta pertalian persaudaraan dan lain-lain. Penggunaan simbol rokok tersebut kemudian memiliki tujuan yang sejalan dengan makna leksikal yang terdapat pada kata rukun. Salah satunya adalah supaya semua anggota masyarakat Sasak yang terlibat pada kegiatan begawe menjadi rukun dan patuh, serta tidak terjadi kericuhan.

f. benang sifat atau dalam bahasa Indonesiadikenal dengan namabenang stokel. 
LINGUA, Vol. 14, No. 1, Maret 2017

p ISSN: 1979 9411; e ISSN: 2442 238X

Http://lingua.pusatbahasa.or.id; Email:presslingua@gmail.com

Center of Language and Culture Studies, Surakarta, Indonesia

Sam'un, Ahmad. 2017. Simbol dan Makna Budaya NyawE? dan Beras Pati: Upaya Pemertahanan Bahasa Masyarakat Sasak. Lingua (2017), 14(1): 79 88.

Benang stokel memiliki maknanya pengikat. Singkatnya benang stokel memiliki fungsi penghubung sekaligus pengikat simbol-simbol yang ada agar semua simbol dan makna yang terkandung di dalamnya pelaksanaan ritual BNBP terhubung secara utuh.

\section{SIMPULAN}

Masyarakat sebagai pemilik budaya dan memiliki fungsi sebagai elemen pemertahan yang paling pital. Pemertahanan budaya masyarakat Sasak sekaligus menjadi hal yang sangat penting dalam rangka mempertahankan keragaman bahasa bangsa Indonesia. Selain itu, bahasa juga dapat menggambarkan pola perilaku masyarakat Sasak. Simbol-simbol budaya BNBP memiliki satu tujuan dalam pelaksanaannya, yaitu membina hubungan yang baik dalam rangka mewujudkan kesatuan dalam kebersamaan dalam proses kehidupan sosial. Budaya BNBP masyarakat Sasak jika dibandingkan dengan kebudayaan yang lainnya memiliki kekhasan yang mengikat perilaku setiap anggota masyarakat Sasak dan juga bahasa yang khas atau berbeda dalam penyebutan simbol-simbol BNBP dengan kelompok masyarakat yang lainnya.

Pernyataan peneliti di atas sejalan dengan apa yang dimaksudkan dalam Hipotesa Sapir-Whorf yakni bahasa merupakan sarana mengkomunikasikan gagasan dan persaaan secara obyektif yang sekaligus juga merupakan ungkap-verbal yang khas bagi nilai-nilai budaya yang bersifat relatif. Bahasa yang berfungsi sebagai alat komunikasi ada dan tumbuh dalam suatu lingkungan budaya, dan nilai-nilai budaya sering terungkap secara khas dalam bahasa setempat. Kekhasan bahasa yang digunakan masyarakat Sasak dalam menyebutkan simbol-simbol BNBP sampai sekarang masih digunakan. Penggunaan bahasa ini pun masih diperuntukkan bagi simbol-simbol yang sama sejak dahulu. Sehingga penulis menyimpulkan bahwa masyarakat Sasak masih telah berhasil mempertahankan bahasa mereka yang sekaligus merupakan keberhasilan menjaga keragaman bahasa yang dimiliki bangsa Indonesia.

\section{DAFTAR PUSTAKA}

Alwi Hasan, Dkk. 2014. Tata Bahasa Baku Bahasa Indonesia. Jakarta Timur: Balai Pustaka.

Abidin, Y.S., Saebani, B. A. 2014. Pengantar Sistem Sosial Budaya di Indoneia. Bandung: CV Pustaka Setia.

Chaer, Abdul. 2011. Lingguistik Umum. Jakarta: PT Rineka Cipta.

Chaer, Abdul dan Agustina, Leonie. 2010. Sosiolinguistik. Jakarta: Rineka Cipta.

Kadarisman, A.E. 2010. Mengurai Bahasa Menyimak Budaya. Malang: UIN-Maliki Press. 
LINGUA, Vol. 14, No. 1, Maret 2017

p ISSN: 1979 9411; e ISSN: 2442 238X

Http://lingua.pusatbahasa.or.id; Email:presslingua@gmail.com

Center of Language and Culture Studies, Surakarta, Indonesia

Sam'un, Ahmad. 2017. Simbol dan Makna Budaya NyawE? dan Beras Pati: Upaya Pemertahanan Bahasa Masyarakat Sasak. Lingua (2017), 14(1): 79 88.

Moleong. 2007. Metodologi Penelitian Kualitatif. Bandung: PT Remaja Rosdakarya.

Muhammad. 2011. Paradigma Kualitatif Penelitian Bahasa. Yogyakarta: Liebe Book Press.

Ratih. 2016. Teori dan Aplikasi Semiotika Michael Riffaterre. Yogyakarta: Pustaka Pelajar.

Sobur. 2013. Semiotika Komunikasi. Bandung:PT Remaja Rosdakarya

Sugihastuti dan Saudah, Siti. 2016. Buku Ajar Bahasa Indonesia Akademik. Yogyakarta: Pustaka Pelajar.

Sumarsono. 2011. Sosiolingistik. Yogyakarta: Pustaka Pelajar.

Sugiyono. 2010. Metodologi Penelitian Pendidikan. Bandung: Alfabeta.

Parera. 2004. Teori Semantik. Jakarta: PT. Gelora Aksara Pratama.

_. 2011. EYD + Pedoman Umum Ejaan Bahasa Indonesia Yang Disempurnakan dan Pedoman Umum Pembentukan Istilah. Bandar Seri Begawan: Victory Inti Cipta.

http://www.pps.unud.ac.id/thesis/kategori-8-linguistik.html/diunduh padatanggal 1 Oktober 2016 pukul. 02. 35 Wita.

https://www.google.co.id/search?ei=B8AjWKvpKcjevAStuJrABQ\&q=artikel+pemerta hanan+bahasa.+pdf\&oq=artikel+pemertahanan+bahasa.+pdf\&gs_l=mobile-gwsserp.12.68838.72119.0.73433.8.8.0.0.0.0.2510.9826.6-1j4j1j1.7.0.0.1c.1.64.mobilegws-serp.5.2.1817.41j0i22i30k1j30i10k1.Q2uhKCkomok/dinduh pada tanggal 2 Oktober 2016 pukul. 08. 38 wita. 
LINGUA, Vol. 14, No. 1, Maret 2017

p ISSN: 1979 9411; e ISSN: 2442 238X

Http://lingua.pusatbahasa.or.id; Email:presslingua@gmail.com

Center of Language and Culture Studies, Surakarta, Indonesia

Sam'un, Ahmad. 2017. Simbol dan Makna Budaya NyawE? dan Beras Pati: Upaya Pemertahanan Bahasa Masyarakat Sasak. Lingua (2017), 14(1): 79 88. 